\title{
Colloidal Hydroxyapatite/Poly(Acrylic Acid) Hybrids Using Calcium Sucrate and Ammoniumdihydrogen Orthophosphate
}

\author{
W.P.S.L. Wijesinghe ${ }^{1,2}$, M.M.M.G.P.G. Mantilaka ${ }^{1,2}$, A.M.C.P. Weerasinghe ${ }^{3}$, \\ K.M. Nalin de Silva ${ }^{4}$, T.P. Gamagedara ${ }^{1,2}$ and R.M.G. Rajapakse ${ }^{1,2,{ }^{*}}$ \\ ${ }^{1}$ Department of Chemistry, Faculty of Science, University of Peradeniya, 20400 Peradeniya, Sri Lanka \\ ${ }^{2}$ Postgraduate Institute of Science, University of Peradeniya, 20400 Peradeniya, Sri Lanka \\ ${ }^{3}$ Department of Botany, Faculty of Science, University of Peradeniya, 20400 Peradeniya, Sri Lanka \\ ${ }^{4}$ Sri Lanka Institute of Nanotechnology, Nanotechnology and Science Park, Mahenwatta, Pitipana, \\ Homagama, Sri Lanka
}

\begin{abstract}
This manuscript is concerned with a simple and novel method to synthesize hydroxyapatite-poly(acylic acid) hybrid materials for broad range of applications. In this method, hydroxyapatite nanoparticles are synthesized using calcium sucrate and ammoniumdihydrogen orthophosphate in the presence of poly(acrylic acid). Increase in poly(acrylic acid) concentration in the synthesis medium results in the increase in the hydrodynamic radius of particle size allowing increased hydration. Poly(acylic acid) tends to control both crystallite size and colloidal stability. Increase in poly(acrylic acid) concentration decreases the crystallite size of the products but considerably increases their shelf life as stable colloidal solutions. Thermo gravimetric analysis shows that there are no combustible or volatile impurities present in these samples. This is further supported by FT-IR studies, which show three types of interactions between hydroxyapatite nanoparticles and poly(acrylic acid).
\end{abstract}

Keywords: Hydroxyapatite, Poly(acrylic acid), Stable colloids, Hybrid materials, Calcium sucrate.

\section{INTRODUCTION}

Stable dispersions of colloidal hydroxyapatite $\left[\mathrm{Ca}_{10}\left(\mathrm{PO}_{4}\right)_{6}(\mathrm{OH})_{2}\right](\mathrm{HA})$ nanoparticles are very useful in biomedical fields. Therefore, it is essential to preserve HA nanoparticles as dispersions for a prolonged period in order to use them in wide-range of biomedical applications [1]. Well-stabilized HA colloids are mainly used in the preparation of HA-coated, biocompatible metal prostheses which are prepared by electrodeposition and dip-coating techniques [2]. Furthermore, colloidal HA nanoparticles are used as delivery systems of peptides, proteins, and DNA therapeutics and as a dental adhesive [3, 4]. Water-soluble, biocompatible polymers are used in the stabilization of HA nanoparticles in their colloidal forms. The resulting material is a polymer/HA hybrid. Furthermore, the phase, morphology and particle size of HA in the composite are controlled by the polymer [5]. Therefore, preparation of such hybrid materials is very important to prepare HA for specific applications.

Bone is an excellent example for an organic/HA nanohybrid which is made up of HA nanoparticles and collagen protein fibers $[6,7]$. Collagen fibers provide a structural framework for the bone and HA nanoparticles

*Address correspondence to this author at the Department of Chemistry, Faculty of Science, University of Peradeniya, 20400 Peradeniya, Sri Lanka; Tel: +94 81 2394442; E-mail: rmgr@pdn.ac.lk are dispersed in collagen matrix $[8,9]$. Therefore, HA nanoparticles are synthesized to use in biomedical applications with structurally and compositionally similar characteristics to natural $\mathrm{HA}$ in bones [10]. However, it is not possible to produce artificial bones with synthetic $\mathrm{HA}$ alone to mimic natural bones, for them to be used in biomedical applications such as bone remodeling, mechanical stability and carrier for drugs/growth factors [11]. Therefore, synthetic HA nanoparticles are combined with biocompatible and biodegradable organic polymers such as poly(acrylic acid) (PAA) [12, 13], poly(lactic acid) [14], poly(caprolactone) [15], and gelatin [16-18] in order to prepare hybrid materials to suit different biomedical applications [19]. These hybrid materials containing biodegradable polymers are degraded after introducing to the body as bone fillers [11]. Mechanical properties of $\mathrm{HA}$ can also be enhanced by combining with the polymers [18, 20]. Therefore, HA-polymer hybrid materials play a vital role in biomedical applications $[18,21]$.

Hybrid materials should be homogenously dispersed when they are used as bone cements and drug delivery agents. Most of the researchers have redispersed HA hybrid materials in different solvents [22, 23]. Generally, PAA is used to deliver drugs individually and also by combining with the other polymers. As such, PAA-HA hybrids also can deliver drugs or growth factors when they are applied in biomedical devices 
[24, 25]. PAA has an ability to bind strongly with hard tissues when it is used as bone cement in various biomedical applications [26, 27]. Chen et al. (2008), investigated the mechanical strength of the calcium phosphate cement-PAA hybrid and shown that mechanical properties have been increased when compared to those of the bare calcium phosphate bone cement [26]. PAA has an ability to absorb enormous amount of water and this water absorption by PAA is an essential feature to maintain colloidal stability of HAPAA hybrid materials [28, 29].

In this study, we have synthesized HA-PAA hybrids, which have very long shelf-life as stable colloids, using a simple and novel method. The colloidal stability of synthesized hybrids is studied by varying the PAA concentration. The preparation method described here is a very simple and an economical method to synthesize HA from readily available minerals such as dolomite and calcite which can be used to prepare calcium sucrate [30-33]. Biological HA nanoparticles have both crystalline and amorphous phases [8, 9, 34], and hence, it is essential to synthesize nanosized $\mathrm{HA}$ in mixture of crystalline and amorphous phases for them to be utilized in biomedical applications. PAA can control the formation of crystalline phase and stabilize the amorphous phase of materials [35]. Mantilaka et al. (2014) have used PAA as a stabilizer to synthesize amorphous calcium carbonate nanoparticles using calcium sucrate as a raw-material. We have used this concept in synthesizing highly dispersible amorphous HA containing HA-PAA Hybrids [35]. In this manuscript, we describe further insight into the preparation and characterization of highly dispersible hybrids of HAPAA which also have long shelf-life as stable colloidal dispersions. This long-term stability is mandatory for these hybrid materials to be used in many technological applications as briefed above.

\section{EXPERIMENTAL}

\subsection{Materials Used}

Calcium oxide (99\%), ammoniumdihydrogen orthophosphate (99\%), sucrose (99\%), acrylic acid (99\%), sodium persulfate (99\%) and sodium hydroxide (99\%) were purchased from Sigma-Aldrich.

\subsection{Preparation of PAA}

A stock solution PAA (0.5 M with respect to the repeat unit) was prepared by polymerizing acrylic acid, at $60{ }^{\circ} \mathrm{C}$, using $1.00 \mathrm{~g}$ of $\mathrm{Na}_{2} \mathrm{~S}_{2} \mathrm{O}_{8}$ and dissolving the solid-formed in $1 \mathrm{M} \mathrm{NaOH}$ solution [35].

\subsection{Preparation of Calcium Sucrate Solution}

We have already documented this procedure elsewhere [36]. Briefly, $2.80 \mathrm{~g}$ of $\mathrm{CaO}$ was dissolved in $100 \mathrm{~mL}$ of $0.5 \mathrm{M}$ sucrose solution to prepare $0.5 \mathrm{M}$ calcium sucrate solution and it was then stirred for $3 \mathrm{~h}$. Next, the solution was allowed to settle-down and thereafter filtered under suction. The resulted solution is calcium sucrate.

\subsection{Preparation of HA-PAA Hybrids}

In the preparation of HA-PAA hybrids, $100.0 \mathrm{~mL}$ of previously prepared PAA solution was added dropwise to $100.0 \mathrm{~mL}$ of the calcium sucrate solution while stirring. Then, $100 \mathrm{~mL}$ of $0.3 \mathrm{M}$ ammoniumdihydrogen orthophosphate (ADO) solution was added (until $\mathrm{Ca} / \mathrm{P}$ ratio of 1.67) to the above reaction mixture using a dropping funnel while stirring. The mixture was further stirred for $12 \mathrm{~h}$ and filtered under suction to obtain a precipitate. The precipitate was washed with distilled water for 3 times and was allowed to dry under ambient laboratory conditions. Four samples were prepared by varying the concentrations of $100 \mathrm{~mL}$ of PAA in samples S1 to S4 to have concentrations, respectively, of $0.5 \mathrm{M}, 0.1 \mathrm{M}, 0.05 \mathrm{M}$ and $0.025 \mathrm{M}$. The key steps of formation of HA-PAA hybrids are shown in Figure 1.

\subsection{Characterization of HA-PAA Hybrids}

Dried samples were carefully milled to a fine powder and thoroughly mixed to homogenize and their powder XRD spectra were recorded with a Siemens D5000 Xray Powder Diffractometer with $\mathrm{Cu} \mathrm{K} \alpha$ radiation of wavelength $\mathrm{k}=0.1540562 \mathrm{~nm}$. The X-ray diffraction (XRD) studies were performed to estimate the crystallite size and to identify the crystal forms of the synthesized HA-PAA hybrids. The resulted XRD patterns were analyzed using the ICDD PDF 2 database. HA-PAA hybrids were further analyzed from the Fourier Transform Infrared (FT-IR) spectroscopy. The FTIR spectra of the products were recorded on a Shimadzu IR Prestige 21 instrument with the $\mathrm{KBr}$ pellet method at dry mass ratio of $1: 40$ product: $\mathrm{KBr}$. Morphologies of the products were observed with the help of Hitachi SU6600 Scanning Electron Microscope (SEM). Thermo Gravimetric Analysis (TGA) was performed to investigate the weight percentages of PAA and water in HA-PAA products using a Scinco STA N-650 instrument, which was performed at a heating rate of $10{ }^{\circ} \mathrm{C} / \mathrm{min}$ in air flow. Particle size distribution of the HA-PAA hybrids were analyzed using Cilas Nano DS Sn 110 Particle Size Analyzer. 


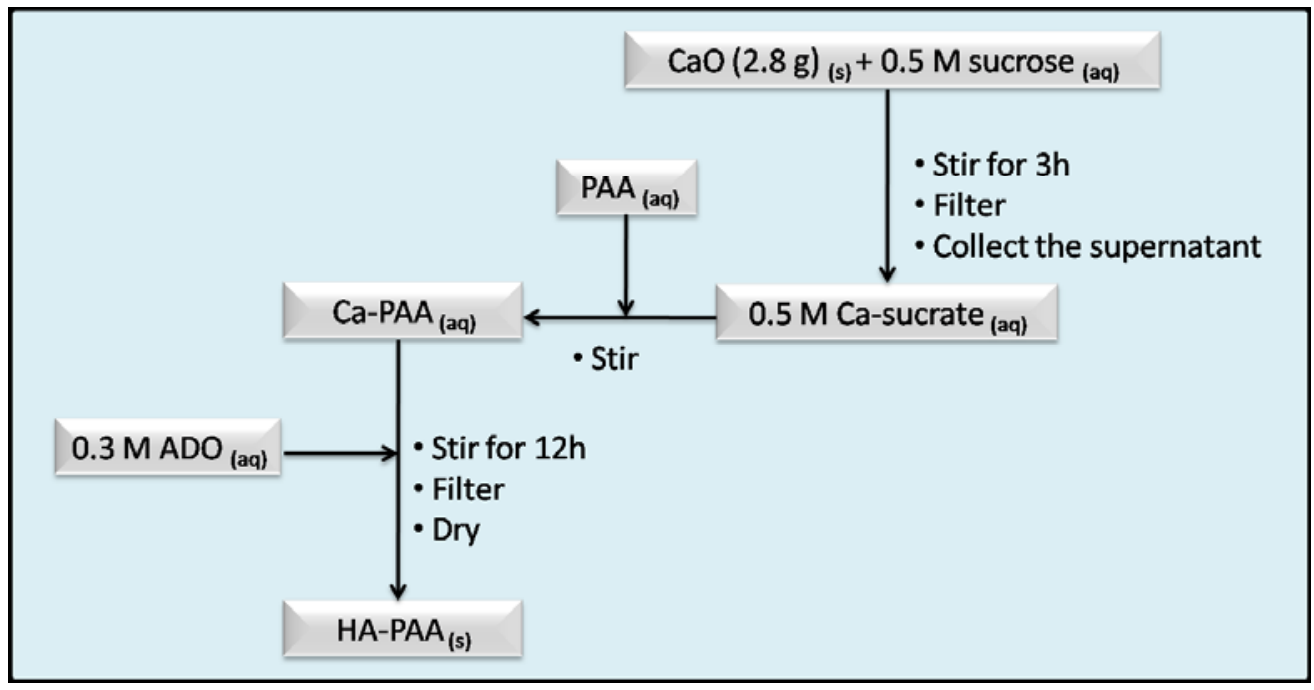

Figure 1: A Process flow diagram for the synthesis of HA-PAA hybrid, where PAA is polyacrylate and ADO is ammoniumdihydrogen orthophosphate.

Prepared hybrids were dispersed in water and were allowed to settle down at the required lengths of times, under ambient laboratory conditions. The settling times were used to investigate the colloidal stability of the HA-PAA hybrids.

\section{RESULT AND DISCUSSION}

\subsection{Synthesis of HA-PAA Hybrids}

We have documented the importance of calcium sucrate as a precursor for the synthesis of $\mathrm{CaCO}_{3}$ and HA nanoparticles, elsewhere [30-33, 36]. When the sodium salt of PAA solution is mixed with the calcium sucrate solution, $\mathrm{Ca}^{2+}$ ions and carboxylate groups of PAA form chelating complexes [35]. These coordinately bonded $\mathrm{Ca}^{2+}$ ions provide essential sites for the formation of $\mathrm{HA}$, thus, colloidal particles of PAA-Ca ${ }^{2+}$ are produced which is observed as turbidity. Once the ADO solution is added dropwise to the mixture of PAA and calcium sucrate, the turbidity of the solution is increased, and later, a white colored precipitate is obtained. The resulted product is HA-PAA hybrid as confirmed by several characterization techniques (videinfra).

\subsection{XRD Studies of HA-PAA Hybrids}

The XRD results of the prepared HA-PAA samples are given in Figure 1. The XRD patterns of all HA-PAA samples, prepared with different amounts of PAA, can be assigned to those of hydroxyapatite (JCPDS card no. 72-1243). The XRD peaks of HA-PAA samples are found at $2 \theta$ values of $25.8^{\circ}, 31.7^{\circ}, 39.7^{\circ}, 46.6^{\circ}, 49.4^{\circ}$ and $53.2^{\circ}$ which are due to reflections from the basal planes of (002), (211), (130), (222), (213), and (004), respectively. The broad diffraction peaks of XRD patterns are observed for samples synthesized with the highest amount of PAA, while, the narrow diffraction peaks are obtained for those synthesized with the lowest amounts of PAA. Increase in broadness of the XRD peaks represents the decrease in the crystallite size of HA crystals. That is because; PAA has an ability to control the crystal growth and the crystallite size of HA. The mean crystallite sizes of the HA-PAA hybrid materials are calculated according to the DebyeSherrer formula using (211) plane [37]. The calculated crystallite sizes of HA synthesized in the presence of $0.5 \mathrm{M}, 0.1 \mathrm{M}, 0.05 \mathrm{M}$, and $0.025 \mathrm{M}$, PAA solutions are $5 \mathrm{~nm}, 8 \mathrm{~nm}, 11 \mathrm{~nm}$, and $15 \mathrm{~nm}$, respectively.

These results clearly indicate that PAA has the ability to control the growth of nuclei to form HA products with less crystallite size of HA. Therefore, prepared HA-PAA hybrid materials can be easily used during bioengineering and biomedical applications of bone tissues.

\subsection{FTIR Studies of HA-PAA Hybrids}

Figure 3 shows the FT-IR spectra of all HA-PAA hybrid samples, which are prepared with different PAA amounts. The spectra of all prepared HA-PAA hybrid samples are very similar with respect to their band positions. The bands centered at $468 \mathrm{~cm}^{-1}, 564 \mathrm{~cm}^{-1}$ and $600 \mathrm{~cm}^{-1}$ are related to the bending vibrations of the phosphate groups of HA [38]. The band centered at $1035 \mathrm{~cm}^{-1}$ and $1101 \mathrm{~cm}^{-1}$ are related to the stretching vibration of the $\mathrm{P}-\mathrm{O}$ bonds which are present in the phosphate groups [38]. The bands at $874 \mathrm{~cm}^{-1}$ and 


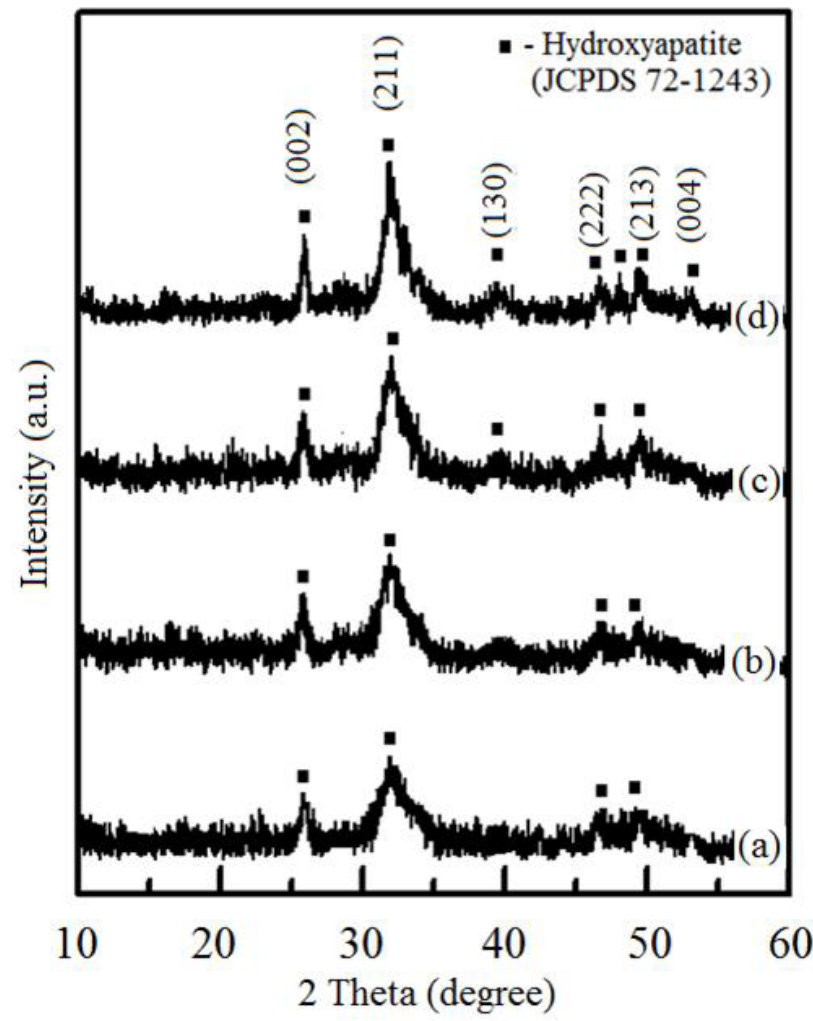

Figure 2: XRD pattern of HA-PAA hybrid synthesized with $100 \mathrm{~mL}$ of (a) $0.5 \mathrm{M}$ (b) $0.1 \mathrm{M}$ (c) $0.05 \mathrm{M}$ (d) $0.025 \mathrm{M}$, PAA solution.

$1458 \mathrm{~cm}^{-1}$ are attributed to the C-O bonds of PAA which are hydrogen bonded with HA [39-41]. The band at $1410 \mathrm{~cm}^{-1}$ is related to the scissoring and bending modes of $\mathrm{C}-\mathrm{H}$ bonds which are in $-\mathrm{CH}_{2-}$, and $-\mathrm{CH}-\mathrm{CO}-$ groups, respectively. The new band appeared at 1560 $\mathrm{cm}^{-1}$ can be assigned to be due to the dissociated carbonyl group [39], which is due to the formation of chelate bonds between carboxylate group and $\mathrm{Ca}^{2+}$ in $\mathrm{HA}$. The broad band around $3400 \mathrm{~cm}^{-1}$ and the sharp band at $1655 \mathrm{~cm}^{-1}$ can be assigned to the stretching vibrations of combined water in the HA-PAA hybrids [36]. The band at $3550 \mathrm{~cm}^{-1}$ is attributed to the bending mode of the hydroxyl groups of HA-PAA hybrid materials [42].

There are three types of interactions that are present in HA-PAA hybrids. They are, (1) H-bonds between surface $\mathrm{OH}$ groups of $\mathrm{HA}$ with carboxylate groups of PAA, and others (2) $\mathrm{H}$-bonds between surface phosphate groups of HA with carboxylate groups of PAA and (3) chelation between surface calcium atoms of $\mathrm{HA}$ with carbonyl oxygen atoms of carboxylate group of PAA [40]. Bhowmik et al. (2007) reported that all of those interactions can be investigated by molecular dynamics simulations [43]. According to the Bhowmik et al., strength of those bonds is higher when the samples prepared under in situ methods when compared to those prepared by exsitu methods.

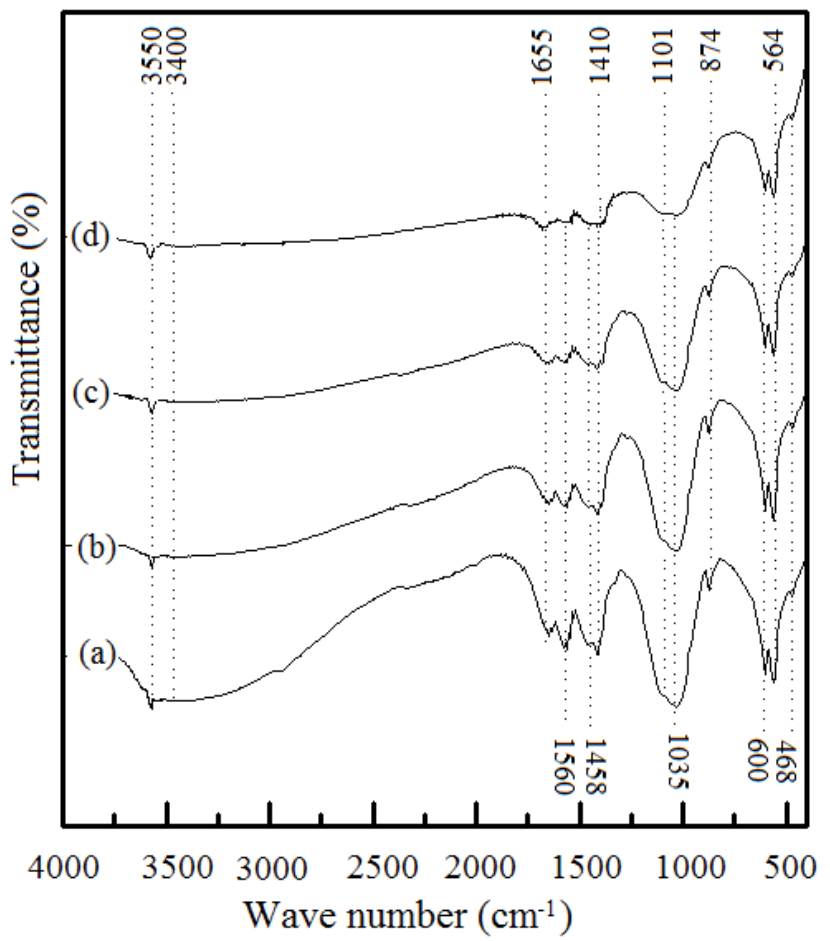

Figure 3: FTIR Spectra of HA- PAA hybrids synthesized with $100 \mathrm{~mL}$ of (a) $0.5 \mathrm{M}$ (b) $0.1 \mathrm{M}$ (c) $0.05 \mathrm{M}$ and (d) $0.025 \mathrm{M}$, PAA solution.

\subsection{Thermal Analytical Studies of HA-PAA Hybrids}

Figure 4 shows the TGA curves of prepared powders of HA-PAA hybrids which have been prepared with different PAA amounts. The mass-loss of HA-PAA hybrid materials at around $100{ }^{\circ} \mathrm{C}$ is attributed to the removal of adsorbed water from HA-PAA hybrids. The mass-loss from $200{ }^{\circ} \mathrm{C}$ to $350^{\circ} \mathrm{C}$ has been observed in all TGA curves, which can be assigned to the combustion of PAA polymer in the hybrid materials. The resulted percentages were $29 \%, 18 \%, 10 \%$ and $6 \%$ which are related to the HA samples prepared with $0.5 \mathrm{M}, 0.1 \mathrm{M}, 0.05 \mathrm{M}$, and $0.025 \mathrm{M}$ of PAA solutions, respectively. There are no any other considerable mass-losses in the TGA curves indicating high purity of these hybrid materials in terms of burnable or volatile materials.

\subsection{Particle Size Distribution Studies of HA-PAA Hybrids}

The particle size distribution of hybrids is an essential character for the determination of colloidal stability of the hybrid. The particle size distribution 


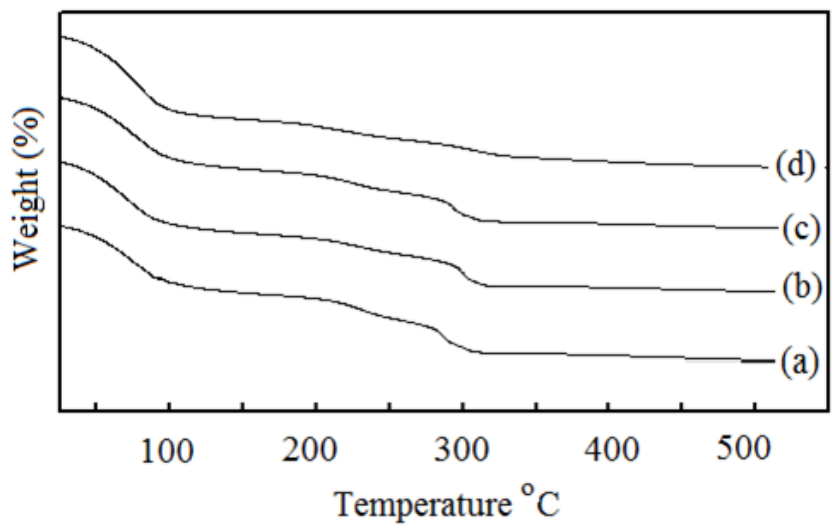

Figure 4: TGA curve of HA- PAA hybrid synthesized with 100 $\mathrm{mL}$ of (a) $0.5 \mathrm{M}$ (b) $0.1 \mathrm{M}$ (c) $0.05 \mathrm{M}$ (d) $0.025 \mathrm{M}$, PAA solution.

curves of the hybrid using DLS technique are given in Figure 5. The average particle sizes of HA colloids prepared using $0.5 \mathrm{M}, 0.1 \mathrm{M}, 0.05 \mathrm{M}$ and $0.25 \mathrm{M}$ PAA solutions are $377.5 \mathrm{~nm}, 277.5 \mathrm{~nm}, 83 \mathrm{~nm}$ and $29.5 \mathrm{~nm}$ respectively. The particle sizes of hybrid materials have been increased with the PAA concentration. According to the particle size distribution studies, the highest average particle size with the highest distribution is obtained with the HA-PAA hybrid which has been prepared with the highest PAA concentration. Lowest particle size and its distribution obtained with the sample which has been prepared with the lowest PAA concentration. That is because, the radius of the hybrid increases with the PAA concentration and ability of absorption of water by the hybrid increases with PAA concentration. Hence, if the hybrid contains highest amount of PAA, that then has a greater ability to absorb higher quantity of water from aqueous medium and to swell and thereby to increase their radius.

\subsection{Colloidal Stability of HA-PAA Hybrid}

Study of colloidal stability of hybrid materials is an essential component when it used as a drug delivery agent or a growth factor during biomedical applications. Therefore, in this study, distilled water was used as a dispersing medium for HA-PAA hybrid materials for the study of colloidal stability of the hybrid materials (Figure

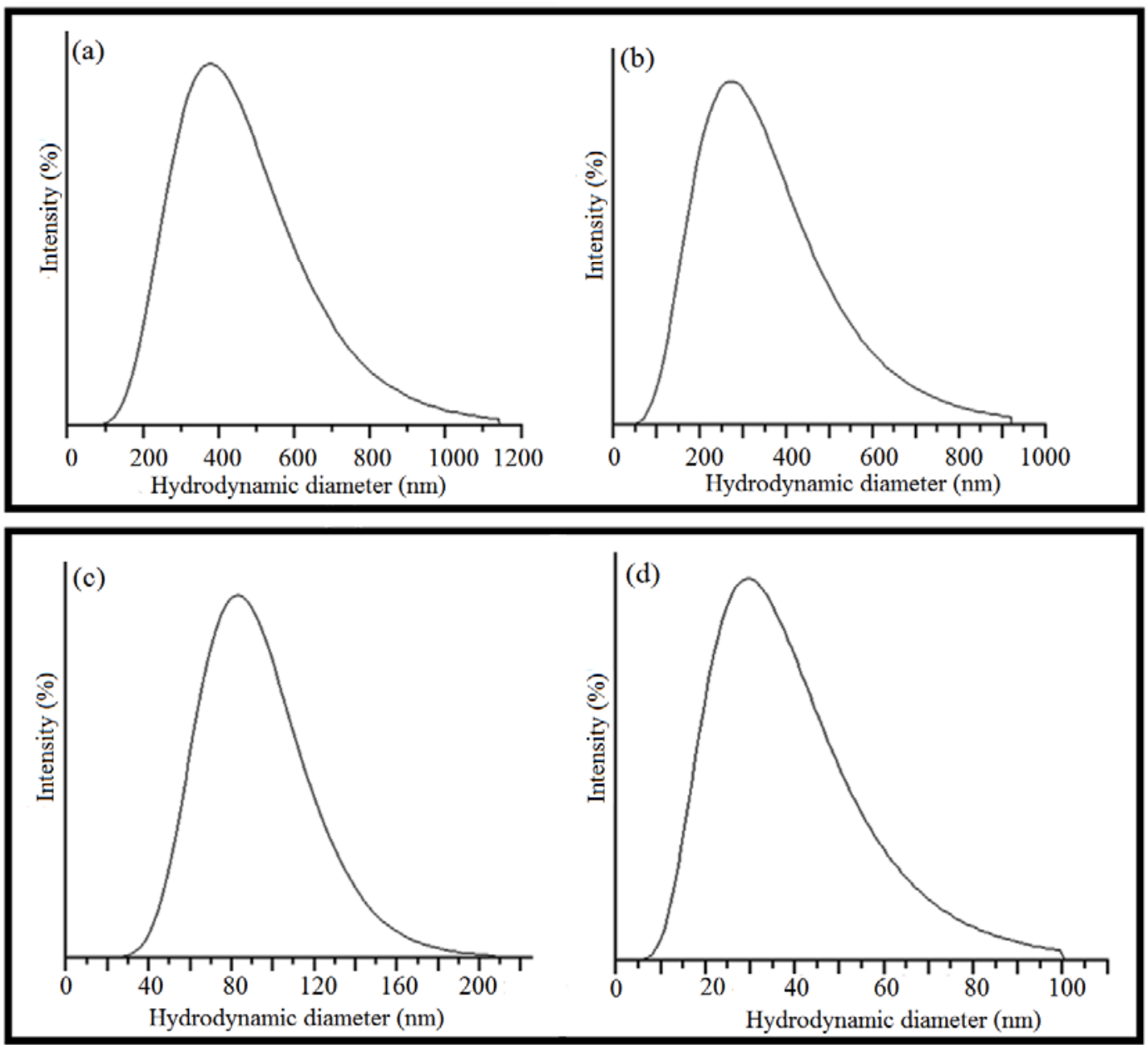

Figure 5: Particle distribution curve of HA- PAA hybrid synthesized with $100 \mathrm{~mL}$ of (a) $0.5 \mathrm{M}$ (b) $0.1 \mathrm{M}$ (c) $0.05 \mathrm{M}$ (d) $0.025 \mathrm{M}$, PAA solution. 


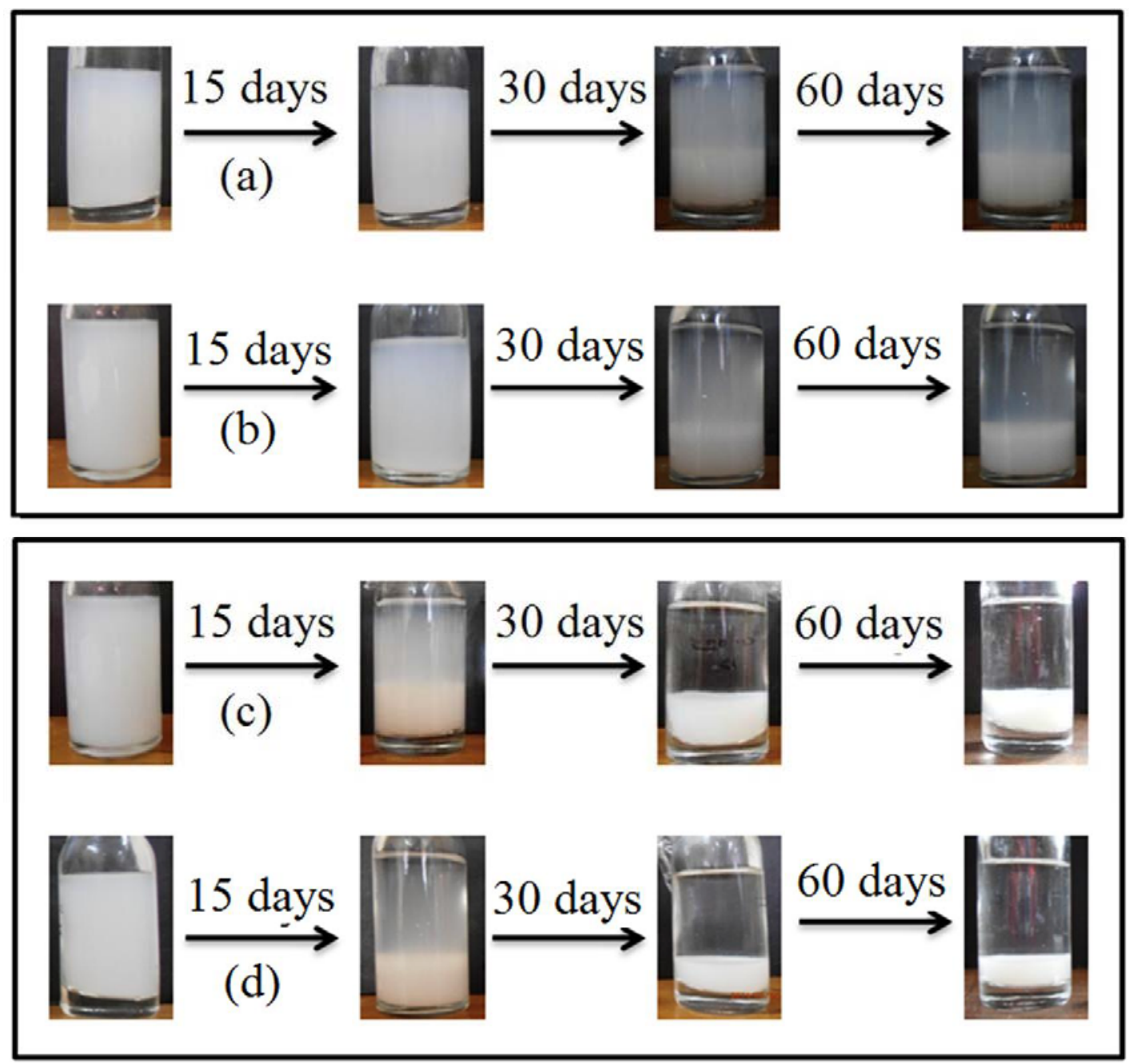

Figure 6: Photographs of colloidal stability study of HA-PAA hybrid synthesized with $100 \mathrm{~mL}$ of (a) $0.5 \mathrm{M}$ (b) $0.1 \mathrm{M}$ (c) $0.05 \mathrm{M}$ (d) $0.025 \mathrm{M}$, PAA solution.

6). The prepared colloids were allowed to sediment and the sedimentation time was measured. According to Figure 6, Samples with highest colloidal stability are "a" and "b" which are prepared by using PAA solutions with $0.50 \mathrm{M}$ and $0.10 \mathrm{M}$ concentrations whereas the samples with lowest colloidal stability are "c" and "d". Sample "a" is more stable than sample "b". In similar manner, sample "c" is stable than the sample "d". Therefore, it can be conclude that the stability of colloidal nanoparticles increases with increasing PAA concentrations. That is because PAA has an ability to absorb water and disperse by increasing their volume and settling time. Thus, the water absorption ability and increment of size of PAA is essential for the colloidal stability of HA-PAA hybrid materials. This is because when PAA concentration is high, that supports to form greater number of hydrogen bonds along with water which is responsible for the colloidal stability and also for the control of the aggregation of HA by the PAA polymer.

\subsection{Morphology of HA-PAA Hybrid}

Figure 7 shows SEM images of colloidal HA-PAA nanocomposite prepared using 0.5 M PAA solution which shows the highest colloidal stability as discussed in previous section. According to our previous study [36], synthesized HA nanoparticles are of needle shape when prepared under ambient conditions $\left(25^{\circ} \mathrm{C}\right)$. However, particles in the HA-PAA nanocomposite have become spherical in shape. This is because, the synthesized HA covered by PAA and the PAA polymer is imposing on the nucleation and growth of $\mathrm{HA}$ particles. Also, their interactions in all directions have made the particles more spherical than elongating in one direction. Figure $\mathbf{8}$ shows SEM images of powdered HA-PAA nanocomposite prepared using 0.5 M PAA solution. Herein, particles have become irregular in shape due to aggregation while preparation of HA-PAA powder from the colloid. 


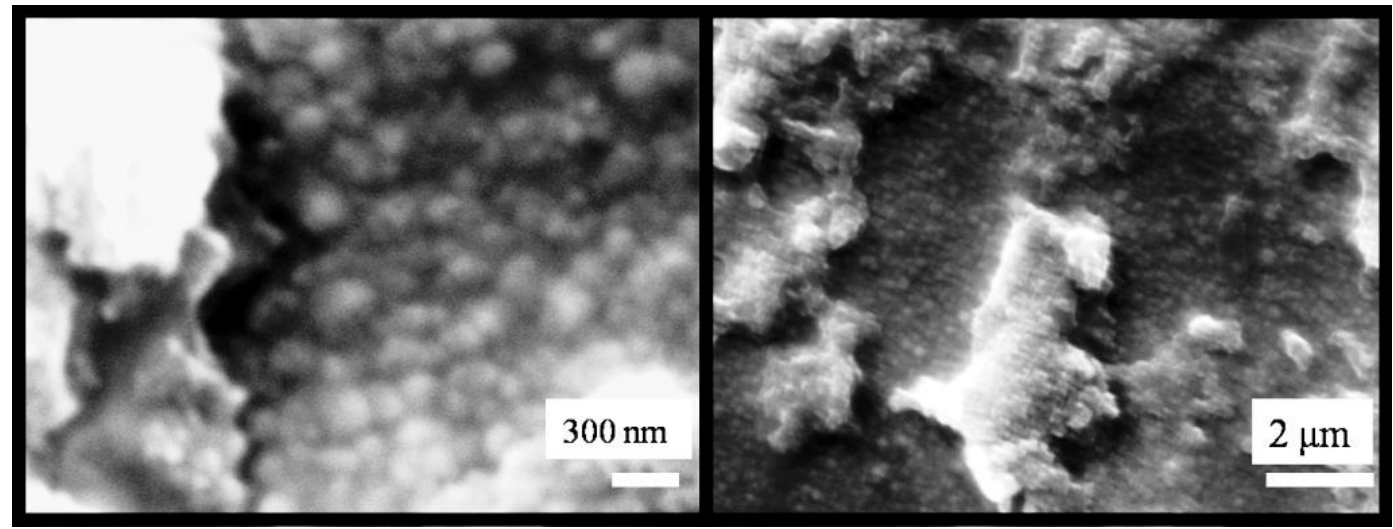

Figure 7: The SEM images of colloidal HA- PAA hybrid material synthesized with $100 \mathrm{~mL}$ of $0.5 \mathrm{M}$ PAA solution at two different magnifications.

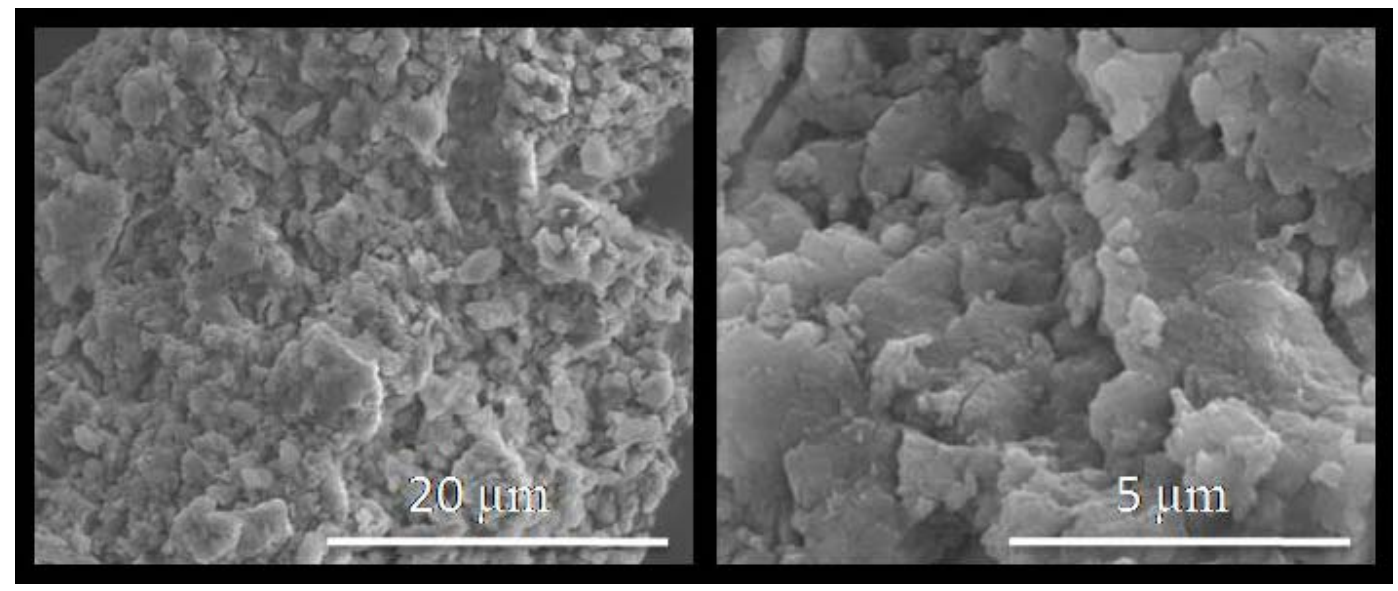

Figure 8: The SEM images of powdered aggregates of HA-PAA hybrid material synthesized with 0.5 M PAA solution at two different magnifications.

\section{CONCLUSIONS}

Stable colloids of HA-PAA hybrid materials are synthesized starting from calcium sucrate and ammonium dihydrogen orthophosphate, for first time. Increase in poly(acrylic acid) concentration decreases the crystallite size of the products but considerably increases their shelf life as stable colloidal solutions. Hydroxyapatite nanoparticles in the hybrid have been stabilized by poly(acrylic acid) from three interactions as, (1) $\mathrm{H}$-bonds between surface $\mathrm{OH}$ groups of $\mathrm{HA}$ with carboxylate groups of PAA, and others (2) $\mathrm{H}$-bonds between surface phosphate groups of HA with carboxylate groups of PAA and (3) chelation between surface calcium atoms of HA with carbonyl oxygen atoms of carboxylate group of PAA. The water absorption ability and increment of size of PAA is essential for the colloidal stability of HA-PAA hybrid since higher PAA concentrations support to form greater number of hydrogen bonds along with water which is responsible for the colloidal stability and also for the control of the aggregation of HA by the PAA polymer. The devised simple method for the synthesis of stable colloidal hydroxyapatite nanoparticles is easily up-scalable.

\section{ACKNOWLEDGEMENTS}

The research is funded by the National Research Council, Sri Lanka (Grant no. NRC/ 11-46). We thank Mr. P. A. D. Abeyrathne and Mr. N. A. N. D. Perera for their technical assistance.

\section{REFERENCES}

[1] Li C, Li G, Liu S, bai J, Zhang A. Spherical hydroxyapatite with colloidal stability prepared in aqueous solutions containing polymer/surfactant pair, Colloid Surf A 2010; 366: 27-33.

http://dx.doi.org/10.1016/j.colsurfa.2010.05.018

[2] Xiao XF, Liu RF. Effect of suspension stability on electrophoretic deposition of hydroxyapatite coatings, Mater Lett 2006; 60: 2627-32.

http://dx.doi.org/10.1016/j.matlet.2006.01.048

[3] Malmsten M, Zauscher S. Colloids and surfaces in biology, Curr Opin In 2013; 18: 379-80.

http://dx.doi.org/10.1016/j.cocis.2013.07.003 
[4] Shojaia MS, Ataia M, Nodehia A, Khanlar LN. Hydroxyapatite nanorods as novel fillers for improving the properties of dental adhesives: Synthesis and application, Dent Mater 2010; 26: 471-82.

http://dx.doi.org/10.1016/j.dental.2010.01.005

[5] Zhou R, Si S, Zhang Q. Water-dispersible hydroxyapatite nanoparticles synthesized in aqueous solution containing grape seed extract, Appl Surf Sci 2012; 258: 3578-83. http://dx.doi.org/10.1016/j.apsusc.2011.11.119

[6] Han Y, Li S, Wang X, Bauer I, Yin M. Sonochemical preparation of hydroxyapatite nanoparticles stabilized by glycosaminoglycans, Ultrason Sonochem 2007; 14: 286-90. http://dx.doi.org/10.1016/j.ultsonch.2006.06.002

[7] Cengiz B, Gokce Y, Yildiz N, Aktas Z, Calimli A. Synthesis and characterization of hydroxyapatite nanoparticles. Colloid Surf A 2008; 32: 229-33.

http://dx.doi.org/10.1016/j.colsurfa.2008.02.011

[8] Peters F, Schwarz K, Epple M. The structure of bone studied with synchrotron X-ray diffraction, X-ray absorption spectroscopy, thermal analysis, Thermochim Acta 2000; 361: 131-8.

http://dx.doi.org/10.1016/S0040-6031(00)00554-2

[9] Paschalis EP, Carlo ED, Betts F, Sherman P, Mendelsohn R, Boskey AL. FTIR Microspectroscopic analysis of human osteonal bone. Calcif Tissue Int 1996; 59: 480-7. http://dx.doi.org/10.1007/BF00369214

[10] Tseng Y, Kuo C, Li Y, Huang C. Polymer-assisted synthesis of hydroxyapatite nanoparticle, Mater Sci Eng C 2009; 29: 819-22.

http://dx.doi.org/10.1016/j.msec.2008.07.028

[11] Habraken WJEM, Wolke JGC, Jansen JA. Ceramic composites as matrices and scaffolds for drug delivery in tissue engineering, Adv Drug Deliver Rev 2007; 59: 234-48. http://dx.doi.org/10.1016/j.addr.2007.03.011

[12] Zhi S, Wan L, Xu Z. Poly(vinylidene fluoride)/poly(acrylic acid)/calcium carbonate composite membranes via mineralization, J Membrane Sci 2014; 454: 144-54. http://dx.doi.org/10.1016/j.memsci.2013.12.011

[13] Liou S, Chen S, Liu D. Synthesis and characterization of needle like apatitic nanocomposite with controlled aspect ratios. Biomaterials 2003; $24: 3981-8$.

http://dx.doi.org/10.1016/S0142-9612(03)00303-X

[14] Niu X, Feng Q, Wang M, Guo X, Zheng Q. Porous nano$\mathrm{HA} /$ collagen/PLLA scaffold containing chitosan microspheres for controlled delivery of synthetic peptide derived from BMP2, J Controll Release 2009; 134: 111-7. http://dx.doi.org/10.1016/j.jconrel.2008.11.020

[15] Esfahani SR, Khorasani S, Lu Z, Appleyard R, Zreiqat H. The influence hydroxyapatite nanoparticle shape and size on the properties of biphasic calcium phosphate scaffolds coated with hydroxyapatite PCL composites, Biomaterials 2010; 31 : 5498-509.

http://dx.doi.org/10.1016/j.biomaterials.2010.03.058

[16] Peter M, Ganesh N, Selvamurugan N, Nair SV, Furuike T, Tamura $\mathrm{H}$, Jayakumar R. Preparation and characterization of chitosan-gelatin/nanohydroxyapatite composite scaffolds for tissue engineering applications, Carbohyd Polym 2010; 80: 687-94.

http://dx.doi.org/10.1016/j.carbpol.2009.11.050

[17] Mohamed KR, El-Rashidy ZM, Salama AA. Preparation and characterization of nano hydroxyapatite/polymeric composites materials. Part I, Mater Chem Phys 2011;130: 561-8.

http://dx.doi.org/10.1016/j.matchemphys.2011.07.024

[18] Hentze HP, Antonietti M. Porous polymers and resins for biotechnological and biomedical applications. Rev Mol Biotechnol 2002; 90: 27-53. http://dx.doi.org/10.1016/S1389-0352(01)00046-0
[19] Murugan R, Ramakrishna S. Development of nanocomposites for bone grafting Compos Sci Technol 2005; 65: 2385-406.

http://dx.doi.org/10.1016/j.compscitech.2005.07.022

[20] Asran AS, Henning S, Michler GH. Polyvinyl alcoholcollagen-hydroxyapatite biocomposite nanofibrous scaffold: Mimicking the key features of natural bone at the nanoscale level. Polymer 2010; 51: 868-76. http://dx.doi.org/10.1016/i.polymer.2009.12.046

[21] Lee S, Shin H. Matrices and scaffolds for delivery of bioactive molecules in bone and cartilage tissue engineering. Adv Drug Deliver Rev 2007; 59: 339-59.

http://dx.doi.org/10.1016/j.addr.2007.03.016

[22] Heinemann S, Rössler S, Lemm M, Ruhnow M, Nies B. Properties of injectable ready-to-use calcium phosphate cement based on water-immiscible liquid. Acta Biomater 2013; 9: 6199-207. http://dx.doi.org/10.1016/. actbio.2012.12.017

[23] Luo J, Qiu S, Zhou X, Lai R, Dong P, Xie X. In situ grafting polyethylene glycol chains onto amorphous calcium phosphate nanoparticles to improve the storage stability and organic solvent redispersibility. Colloid Surface A 2014; 444: 81-8.

http://dx.doi.org/10.1016/j.colsurfa.2013.12.041

[24] Adnadjevic B, Jovanovic J. A comparative kinetics study of isothermal drug release from poly(acrylic acid) and poly(acrylic-co-methacrylic acid) hydrogels. Colloid Surface B 2009; 69: 31-42.

http://dx.doi.org/10.1016/j.colsurfb.2008.10.018

[25] Nho Y, Park Jk, Lim Y. Preparation of poly(acrylic acid) hydrogel by radiation crosslinking and its application for mucoadhesives. Polymer 2014; 6: 890-8.

http://dx.doi.org/10.3390/polym6030890

[26] Chena W, Jub C, Wanga J, Hunga C, Lin JC. Brittle and ductile adjustable cement derived from calcium phosphate cement/polyacrylic acid composites. Dent Mater 2008; 24: 1616-22.

http://dx.doi.org/10.1016/j.dental.2008.03.032

[27] Es-Souni M, Brandies HF, Zaporojshenko V. On the interaction of polyacrylic acid as a conditioning agent with bovine enamel. Biomaterials 2002; 23: 2871-8. http://dx.doi.org/10.1016/S0142-9612(01)00414-8

[28] Witono JR, Noordergraaf IW, Heeres HJ, Janssen LPBM. Water absorption, retention and the swelling characteristics of cassava starch grafted with polyacrylic acid. Carbohyd Polym 2014; 103: 325-32.

http://dx.doi.org/10.1016/j.carbpol.2013.12.056

[29] Hosseinzadeh $H$, Sadeghzadeh $M$, Babazadeh $M$. Preparation and properties of carrageenan-g-poly(acrylic acid)/bentonite superabsorbent composite. J Biomater Nanobiotechnol 2011; 2: 311-7.

http://dx.doi.org/10.4236/jbnb.2011.23038

[30] Mantilaka MMMGPG, Karunaratne DGGP, Rajapakse RMG, Pitawala HMTGA. Precipitated calcium carbonate/ poly(methyl methacrylate) nanocomposite using dolomite: synthesis, characterization and properties. Powder Technol 2013; 235: 628-32.

http://dx.doi.org/10.1016/j.powtec.2012.10.048

[31] Mantilaka MMMGPG, Pitawala HMTGA, Rajapakse RMG, Karunaratne DGGP. Upul Wijayantha KG. Formation of hollow bone-like morphology of calcium carbonate on surfactant/polymer templates. J Cryst Growth 2014; 392: 529. http://dx.doi.org/10.1016/j.jcrysgro.2014.02.007

[32] Mantilaka MMMGPG, Pitawala HMTGA, Karunaratne, DGGP Rajapakse RMG. Nanocrystalline magnesium oxide from dolomite via poly(acrylate) stabilized magnesium hydroxide colloids. Colloid Surface A 2014; 443: 201-8. http://dx.doi.org/10.1016/j.colsurfa.2013.11.020 
[33] Mantilaka MMMGPG, Wijesinghe WPSL, Pitawala HMTGA, Rajapakse RMG, Karunaratne DGGP. Surfactant-assisted synthesis of pure calcium carbonate nanoparticles from Sri Lankan dolomite. J Natn Sci Foundation Sri Lanka 2014; 42: 221-8.

http://dx.doi.org/10.4038/jnsfsr.v42i3.7398

[34] Dorozhkin SV. Amorphous calcium (ortho)phosphates. Acta Biomater 2010; 6: 4457-75. http://dx.doi.org/10.1016/j.actbio.2010.06.031

[35] Mantilaka MMMGPG, Rajapakse RMG, Pitawala HMTGA, Karunaratne, DGGP. Preparation of amorphous calcium carbonate nanoparticles from impure dolomitic marble with the aid of poly(acrylic acid) as a stabilizer. Adv Powder Technol 2014; 25: 591-8. http://dx.doi.org/10.1016/j.apt.2013.09.008

[36] Wijesinghe WPSL, Mantilaka MMMGPG, Premalal EVA, et al. Facile synthesis of both needle-like and spherical hydroxyapatite nanoparticles: Effect of synthetic temperature and calcination on morphology, crystallite size and crystallinity. Mater Sci Eng C 2014; 42: 83-90. http://dx.doi.org/10.1016/j.msec.2014.05.032

[37] Pang YX, Bao X. Influence of temperature, ripening time and calcination on the morphology and crystallinity of hydroxyapatite nanoparticles. J Eur Ceram Soc 2003; 23: 1697-704.

http://dx.doi.org/10.1016/S0955-2219(02)00413-2
[38] Gu C, Katti DR, Katti KS. Photoacoustic FTIR spectroscopic study of undisturbed human cortical bone. Spectrochim Acta A 2013; 103: 25-37. http://dx.doi.org/10.1016/.saa.2012.10.062

[39] El-Bahy GS, Abdelrazek EM, Allam MA, Hezma AM. Characterization of in situ prepared nanohydroxyapatite/polyacrylic acid (HAp/PAAc) biocomposites. J Appl Polym Sci 2011; 122: 3270-6. http://dx.doi.org/10.1002/app.34413

[40] Katti KS, Turlapati P, Verma D, Bhowmik R, Gujjula PK, Katti DR. Static and dynamic mechanical behavior of hydroxyapatite-polyacrylic acid composites under simulated body fluid. Am J Biochem Biotechnol 2006; 2: 73-9. http://dx.doi.org/10.3844/ajbbsp.2006.73.79

[41] Liu Q, Wijn JR, Blitterswijk CAV. Nano-apatite/polymer composites: mechanical and physicochemical characteristics. Biomaterials 1997; 18: 1263-70. http://dx.doi.org/10.1016/S0142-9612(97)00069-0

[42] Wang $\mathrm{P}$, Li C, Gong H, Jiang X, Wang H, Li K. Effects of synthesis conditions on the morphology of hydroxyapatite nanoparticles produced by wet chemical process. Powder Technol 2010; 203: 315-21. http://dx.doi.org/10.1016/j.powtec.2010.05.023

[43] Bhowmik R, Katti KS, Katti D. Molecular dynamics simulation of hydroxyapatite polyacrylic acid interfaces. Polymer 2007; 48: 664-74.

http://dx.doi.org/10.1016/j.polymer.2006.11.015 